Pesquisa e Reflexão em Educação Básica

\title{
Estudos sobre transição para a vida adulta: perspectivas para novas pesquisas
}

Fernanda Arantes e Silva ${ }^{1}$

\begin{abstract}
Resumo:
Neste artigo é apresentada revisão bibliográfica acerca dos estudos sobre transição de jovens para a vida adulta realizados nos países do Hemisfério Norte, da América Latina e do Brasil. A metodologia de pesquisa bibliográfica foi adotada e a base de dados utilizada para o levantamento foi o Portal de Periódicos da CAPES. Para a revisão privilegiou-se os trabalhos desenvolvidos na área das Ciências Sociais e Educação entre os anos 2007 e 2020. Os descritores utilizados para busca foram: juventude, jovens, jovens adultos, prolongamento da juventude, transição, transição para a vida adulta, trânsito até a adultez, vida adulta e curso de vida. Por meio da revisão foi possível identificar caminhos para a realização de novos estudos sobre o tema no Brasil. São necessárias pesquisas que tenham como ponto central as desigualdades raciais, de gênero e territoriais e o modo como elas afetam a transição dos jovens para a idade adulta. Os estudos também precisam considerar outros aspectos da vida das moças e rapazes, como a participação política, a atuação em grupos e coletivos juvenis, entre outros. No Brasil são escassos os estudos sobre apoios estatais voltados aos jovens nos processos de transição, configurando-se um campo profícuo de pesquisa.
\end{abstract}

\section{Palavras-chave: \\ Vida adulta. Transição. Juventude.}

\section{Studies on transition to adulthood: perspectives for new research}

Abstract: This paper presents a literature review about the studies on the transition of young people to adult life carried out in the countries of the Northern Hemisphere, Latin America and Brazil. The bibliographic research was conducted using the Portal de Periódicos da CAPES as primary database. The review focused on studies developed in the areas of Social Sciences and Education between the years 2007 and 2020. The descriptors used for the search were: youth, boyhood, young adults, extension of youth, transition, transition to adulthood, transit until adulthood, adulthood and life course. Through the review it was possible to identify ways to carry out new studies on the topic in Brazil. Research that focuses on racial, gender and territorial inequalities and how they affect young people's transition to adulthood is needed. Studies also need to consider other aspects of the lives of girls and boys, such as political participation, action in youth groups and collectives, among others. In Brazil, studies on state support aimed at young people in the transition processes are scarce, setting up a fruitful field of research.

Keywords: Adult life. Transition. Youth. 


\section{Estudios sobre la transición a la edad adulta: perspectivas para nuevas investigaciones}

Resumen: Este artículo presenta una revisión bibliográfica sobre los estudios sobre la transición de los jóvenes a la vida adulta realizados en los países del hemisferio norte, América Latina y Brasil. Se adoptó la metodología de investigación bibliográfica y la base de datos utilizada para la encuesta fue el Portal de Revistas CAPES. Para la revisión se privilegió el trabajo desarrollado en el área de Ciencias Sociales y de la Educación entre los años 2007 y 2020. Los descriptores utilizados para la búsqueda fueron: juventud, juventud, adultos jóvenes, extensión de la juventud, transición, transición a la edad adulta, tránsito hasta la edad adulta, la edad adulta y el curso de la vida. A través de la revisión fue posible identificar formas de realizar nuevos estudios sobre el tema en Brasil. Se necesitan investigaciones que se centren en las desigualdades raciales, de género y territoriales y en cómo afectan la transición de los jóvenes a la edad adulta. Los estudios también deben considerar otros aspectos de la vida de las niñas y los niños, como la participación política, la actuación en grupos y colectivos juveniles, entre otros. En Brasil, son escasos los estudios sobre el apoyo estatal a los jóvenes en los procesos de transición, lo que configura un campo de investigación fructífero.

Palabras clave: Vida adulta. Transición. Juventud.

\section{Introdução}

Pode-se considerar como estopim para o início dos estudos sobre essa fase da vida o que foi denominado de prolongamento da juventude, ou seja, o período da juventude passou a se estender no tempo. Nos países desenvolvidos, observou-se que, após o fim da segunda guerra mundial, houve alteração na idade em que os jovens entravam no mercado de trabalho e deixavam a casa dos pais para formar uma nova unidade familiar. Com vistas a compreender essas mudanças, em fins dos anos 1980 e início dos 1990, pesquisadores europeus debruçaram-se sobre essa problemática.

No Brasil ainda são poucas as pesquisas, na área da Educação e Ciências Sociais, dedicadas a compreender os processos de transição para a vida adulta percorridos por moças e rapazes. Essa escassez também pode ser observada nos estudos empreendidos pelos nossos vizinhos latino-americanos.

Com o objetivo de contribuir com o tema de estudo e suscitar caminhos para a realização de pesquisas sobre transição para a vida adulta no contexto brasileiro, este artigo apresenta um exercício de revisão bibliográfica. Cabe ressaltar que a proposta não é a de fazer um Estado da Arte sobre o tema e nem um levantamento exaustivo das produções, mas mapear as pesquisas realizadas nas áreas de Ciências Sociais e Educação.

O artigo está dividido em cinco partes: a primeira parte apresenta a metodologia adotada para a revisão de literatura. Na segunda, apresentam-se os desdobramentos das pesquisas efetivadas no Hemisfério Norte, destacando as produções de pesquisas que, considerou-se, colocaram as discussões sobre transição para a vida adulta em cena e contribuíram para consolidar um campo de estudo. Em seguida, verificam-se os desdobramentos das pesquisas nos países da América Latina e, na quarta parte são apresentadas as produções brasileiras. Por fim, são esboçadas considerações sobre a produção levantada e perspectivas para a realização de novas pesquisas.

\section{Metodologia}

Para a revisão da literatura dos estudos sobre transição para a vida adulta foi adotada a metodologia de pesquisa bibliográfica. A pesquisa bibliográfica tornou-se um procedimento muito utilizado nos trabalhos de caráter exploratório e descritivo, "casos em que o objeto de estudo proposto é pouco 
estudado, tornando difícil a formulação de hipóteses precisas e operacionalizáveis" (LIMA; MIOTO, 2007). Esta metodologia permite ao pesquisador mapear com criticidade o que já foi produzido acerca do seu objeto de estudo, além de indicar quais são as lacunas existentes, permitindo que a delimitação do estudo a ser realizado contribua de forma efetiva para o tema de estudo.

Para a revisão aqui proposta, tomou-se como ponto de partida o extenso referencial teórico apresentado por Melissa Mattos Pimenta (2007) em sua tese de doutorado. A autora identificou as principais contribuições das pesquisas europeias e um guia para a leitura mais atenta dos trabalhos indicados por ela. A revisão também foi realizada por meio do Portal de Periódicos da CAPES, que reúne uma vasta produção científica nacional e internacional. Os descritores utilizados para busca foram: juventude, jovens, jovens adultos, prolongamento da juventude, transição, transição para a vida adulta, trânsito até a adultez, vida adulta e curso de vida. A janela temporal adotada para o levantamento foi de 2007 a 2020.

Importante destacar que, durante a revisão localizou-se produção profícua sobre o tema da transição para a vida adulta na área da Psicologia, a partir do enfoque do adulto emergente cunhado por Jeffrey Arnett (professor do Departamento de Psicologia da Universidade Clark, em Massachusetts). Seu principal interesse de pesquisa é o emergir na idade adulta. Contudo, a revisão realizada neste artigo privilegiou os trabalhos desenvolvidos na área das Ciências Sociais e Educação.

Para os estudos sobre transição para a vida adulta realizados nos países do Hemisfério Norte e da América Latina, a revisão de literatura concentrou-se nos artigos científicos publicados sobre o tema, fossem eles teóricos ou de resultados de pesquisa empíricas. Para as produções brasileiras o leque foi ampliado, incluindo também a leitura de dissertações e teses que foram defendidas até 2016. Por fim, cabe reiterar que o objetivo não foi realizar um estado da arte sobre o tema, e sim levantar as principais produções realizadas e apresentar caminhos para a realização de novas pesquisas.

\section{Hemisfério Norte: desdobramentos das pesquisas sobre transição}

Como abordado anteriormente, em fins de 1980 e início dos anos 1990 o prolongamento da juventude e as mudanças causadas nos processos de transição para a vida adulta passaram a ser objeto de estudo de pesquisadores europeus. Até início dos anos 2000, realizou-se um conjunto de pesquisas e criaram-se grupos de investigação a fim de ampliar o alcance das pesquisas. Essas primeiras produções serão aqui apresentadas com mais detalhes.

Em 1987, foi criado o Grupo de Investigação em Educação e Trabalho (GRET) por pesquisadores da Universidade Autônoma de Barcelona. O grupo lançou mão de biografias de itinerários para apreender a juventude, entendida como um trecho da biografia de transição, como um processo social de busca de autonomia econômica e de emancipação plena da família, conquistado com o acesso a um domicílio próprio e independente. Para a realização das pesquisas, o GRET apoiou-se em dois tempos chave: transição escola-trabalho e transição familiar.

As pesquisas realizadas pelo GRET visavam reconstruir e identificar os itinerários, de êxito ou de fracasso, que delineiam os jovens na tomada de decisões e oportunidades no que diz respeito à transição profissional e emancipação familiar, relacionando-os com a estrutura social e a construção de expectativas e oportunidades, a partir da metodologia de corte longitudinal. Nas pesquisas, o grupo encontrou cinco modalidades de transição: êxito precoce; trajetórias operárias; trajetórias desestruturadas; trajetórias de precariedade e aproximações sucessivas (CASAL; MERINO; GARCIA, 2011).

A perspectiva biográfica de itinerários contribuiu para o estudo da transição, ao incluir nas análises as variáveis tempo, por meio de estudos longitudinais, as expectativas dos jovens e as trajetórias por eles construídas. Os jovens tiveram papel ativo no processo de transição para a vida adulta e seus projetos foram estudados levando em consideração as influências das estruturas sociais. Os pesquisadores do GRET também inferiram que há disparidades nas formas de 
emancipação familiar, uma vez que os impulsos iniciais são variáveis, sendo também diverso o tempo em cada biografia construída pelos atores.

Na França, Oliver Galland (1990) identifica que a explosão escolar foi um dos motivos de adiamento da entrada no sistema laboral, que também pode ser observado nos demais países desenvolvidos e em desenvolvimento. Ademais, houve uma postergação na entrada em uma profissão, uma vez que o término dos estudos não significou a entrada imediata no sistema de emprego e que o acesso ao mercado de trabalho tornou-se um período "de exploração, de espera e de tateamentos" (GALLAND, 1997, p. 10).

Para Galland (1997), diante das transformações ocorridas ao longo do século XX, colocou-se em xeque o modelo de instalação da transição para a idade adulta. Tal modelo consistia na transposição de três etapas: entrar na vida profissional, partir da casa da família e formar uma nova família. Com suas pesquisas longitudinais de coortes etárias, utilizando indicadores estatísticos, observou a dessincronização das etapas que serviam como marcadores nas transições tradicionais, corroborando para a ideia de prolongamento da juventude.

Com o objetivo de realizar pesquisas comparativas entre alguns países, em 1994 foi formada a European Society for Regional and International Social Research (EGRIS)', que, até meados dos anos 2000, realizou três estudos. O primeiro, de caráter geral, analisou as semelhanças e divergências nos processos de transição para a vida adulta. Os estudos empreendidos identificaram a diversidade existente nos processos de transição e nos modos em que as políticas são organizadas nos diferentes países. Por exemplo, nos países do norte europeu e os da região mediterrânea diferem no modo de organizar os sistemas educativos, mercado de trabalho, proteção social, seguridade e nas políticas voltadas para os jovens. Dessa forma, uma trajetória identificada como de risco em um país não necessariamente o será em outro.

O segundo estudo realizado visou compreender os enquadramentos familiares em que as transições ocorriam. As investigações foram realizadas no âmbito do projeto Family and Transitions in Europe (FATE) ${ }^{2}$ e inferiram que, nos países do sul da Europa (Portugal, Espanha, Itália e Grécia), onde os Estados Sociais são relativamente poucos desenvolvidos, a família sempre exerceu papel importante no suporte e na gestão das transições; já nos países do norte (Alemanha, Holanda e Dinamarca), os apoios estatais eram reduzidos, o que levou as famílias a assumirem a linha de frente do apoio às transições (PAIS; CAIRNS; PAPPÁMIKAIL, 2005).

O EGRIS também desenvolveu o projeto Trajetórias desencaminhadoras, com o objetivo de apreender como ocorriam as políticas voltadas para apoiar os jovens nos processos de transição, principalmente entre escola-trabalho. A conclusão do projeto mostrou que as políticas estão pautadas na lógica da linearidade e criam uma ordem artificial de transição. Os resultados mostraram que as políticas mais propensas a conduzir as trajetórias desencaminhadoras ${ }^{3}$ são aquelas que não dialogam com as perspectivas subjetivas dos jovens e desmotivam os jovens exigindo mais educação sem ser capaz de oferecer formação adequada (DU BOIS-REYMOND; BLASCO, 2004).

As pesquisas realizadas pelo GRET, pelo EGRIS e por Olivier Galland serviram como guias para a realização de outros estudos sobre transição para a vida adulta em diversos países. As contribuições trazidas por elas e apresentadas acima ofereceram um panorama dos caminhos possíveis e seguidos para compreender o movimento dos jovens em direção à idade adulta.

\footnotetext{
1 Fundada em 1993, iniciou os trabalhos em 1994, a rede foi composta pelos seguintes países: Dinamarca, Alemanha, Irlanda, Itália, Países Baixos, Portugal, Espanha e Reino Unido.

20 projeto Famílias e transições na Europa combinou abordagens quantitativas e qualitativas, com o propósito de explorar as experiências de transição relacionadas com educação e trabalho, entrada no mercado de trabalho, situação residencial, relações intergeracionais, apoio familiar e estatal e planos de futuro (PAIS; CAIRNS; PAPPÁMIKAIL, 2005).

3 “Estruturas (políticas) que intentam e prometem levar os jovens à integração social através da orientação, educação, formação e políticas de bem-estar e mercado de trabalho, mas de fato reproduzem ou reforçam os riscos de exclusão social que sofre este coletivo" (DU BOIS-REYMOND; BLASCO, 2004).
} 
No levantamento realizado, foram localizadas 31 publicações de resultados de pesquisas sobre o tema entre os anos 2007 e 2020. Observou-se que estudos desenvolvidos nesse período elegeram públicos específicos e lançaram mão de pesquisas qualitativas, privilegiando o uso de entrevistas. Poucas se propuseram a desenvolver estudos comparativos entre diferentes países e o principal enfoque foi a transição entre escola e trabalho, seguido dos arranjos e das novas relações familiares. Apenas quatro pesquisas propuseram-se a compreender os apoios estatais disponíveis aos jovens para moverem-se para a vida adulta.

As alterações ocorridas no mercado de trabalho, sobretudo a partir de 1990, como a flexibilização, a precarização dos contratos, as jornadas parciais e o desemprego juvenil (PAIS, 1991), colocaram em evidência o tema da transição escola-trabalho. Desse modo, diversas pesquisas tiveram por objetivo compreender como diferentes públicos realizavam essa transição e, em algumas, com quais apoios os jovens podiam contar.

Um conjunto de estudos, dentre as 31 publicações mapeadas, buscou apreender como jovens com deficiência realizavam a transição da escola para a vida profissional. Identificou-se que há diferenças nas trajetórias quando se estuda em escolas "especiais" ${ }^{\text {ou }}$ tradicionais. $\mathrm{O}$ panorama encontrado foi este:

a. Os jovens escoceses com deficiência, que realizaram sua escolarização em escolas especiais, tendem a não ingressar no mercado de trabalho (RIDDEL, 2009).

b. Os jovens com deficiência em Oregon (EUA) estudam somente até o término da educação básica, o que dificulta a inserção deles na vida ativa (PORVENMIRE-KIRK; LINDISTRON; BULLIS, 2009).

c. Os jovens com deficiência na Espanha (ESTEFANIA, 2011; NOELL et al., 2015) e em Portugal (FANZERES; CRUZ-SANTO; SANTOS, 2016) têm como principais suportes a escola e as organizações da sociedade civil para realizarem a transição para a vida adulta.

d. Os jovens com deficiência na Itália estão incluídos nas escolas comuns e, para auxiliá-los no processo de inclusão escolar e profissional, o governo italiano desenvolve o projeto de vida, que consiste em uma ação pedagógica, um planejamento didático produzido no contexto escolar a partir do Plano Educativo Individualizado. A elaboração desse plano envolve uma equipe de profissionais e a família do jovem, estabelecendo-se uma rede de suporte (MEIRELES; DAINESE; FRISO, 2017).

Os jovens em situação de vulnerabilidade social e o modo como se inseriam no mercado de trabalho também foram objetos de pesquisas. Uma das pesquisas buscou compreender como jovens ingleses pobres, com fracas habilidades de leitura e dificuldades com matemática, realizavam a transição entre a escola e o trabalho e quais estratégias desenvolviam para sanar as dificuldades em decorrência da defasagem escolar (SIMPSON; CIESLIK, 2007). Pesquisas realizadas com jovens em situação de rua em diversos países aferiram que eles não reuniam condições favoráveis para seguir os padrões típicos de transição para a idade adulta. Os empregos por eles conquistados eram em sua maioria sazonais e, por serem menos escolarizados, eram os primeiros a serem demitidos (MCCARTHY; WILLIAMS; HAGAN, 2009).

No Canadá, pesquisa realizada com jovens moradores de abrigos mostrou que eles enfrentam dificuldades para entrar no mercado de trabalho. São jovens com ampla rede de suporte, como de amigos e trabalhadores sociais para realizarem a transição, no entanto muitos criam uma relação de dependência com seus suportes, o que dificulta o processo de transição (GOYETTE, 2010). Na Espanha, três pesquisas analisaram as condições de transição para a vida adulta de jovens em situação de vulnerabilidades. Na primeira, Fonayet identificou que abandonar a escola e começar a trabalhar, com vistas a superar a escassez em que viviam, era estratégia empregada

4 Instituição especializada, destinada a prestar atendimento a educandos portadores de deficiência. 
por jovens espanhóis que estavam abaixo da linha da pobreza. Porém, a inserção precoce não era garantia para sair da situação precária em que viviam, pois, os jovens acabavam reproduzindo um círculo de pobreza (FONAYET, 2015).

As outras duas pesquisas tiveram como objeto de estudo jovens que vivem sob a tutela do governo espanhol, sendo que uma delas investigou o Programa de residência de apoio a transição para a vida adulta, que assegura aos jovens tutelados de 16 a 21 anos recursos residenciais para que possam desenvolver sua autonomia, concluir os estudos e entrar no mercado de trabalho. A pesquisa revelou que os jovens que permanecem no programa são aqueles que aceitam as orientações educativas, as regras do recurso residencial e possuem um projeto de emancipação (COMASÒLIVAS MOYA; SALA-ROCA; MARZO ARPÓN, 2017).

A segunda pesquisa analisou a transição para a vida adulta de jovens estrangeiros ex-tutelados. O estudo inferiu que, ao completar a maioridade, esses jovens deixam de receber o apoio do estado, sendo obrigados a transitar para a vida adulta em idades inferiores ao que é habitual na Espanha. São jovens que possuem muitas dificuldades para se inserirem no mercado de trabalho, uma vez que seu grau de escolaridade é menor que dos jovens não tutelados. Contudo, o trabalho possui um lugar central para a vida deles, pois é fundamental para a conquista da autonomia e o desenvolvimento pessoal e social (PALMA-GARCÍA; MOSQUERA; GONZÁLEZ, 2019).

Além das pesquisas focadas nos jovens em vulnerabilidade social, identificou-se um conjunto de estudos espanhóis que se debruçaram na análise das condições de inserção laboral dos jovens elegendo como pano de fundo a crise no mercado de trabalho. Izaskun Artegui Alcaide (2017) analisou as interferências que as transformações ocorridas no mercado de trabalho tiveram na diversificação dos tempos impactando nos processos de transição para a vida adulta dos jovens que passaram a ter a incerteza como fator presente em suas vidas. Para realizar seu estudo entrevistou jovens que se aproximavam de um modelo de transição mais linear e jovens que se distanciavam desse modelo. Os dados que, tanto os que optaram por trajetórias mais estáveis, como os que flexibilizaram, se encontram protegidos diante da incerteza e sofrem de forma menos preocupantes seus efeitos. Os jovens que convivem com a inconstância de trabalho buscam estratégias de espera, o que minimiza seus efeitos. Já para os jovens que se encontram em situação de precariedade continuada, a incerteza toma um lugar importante e prejudicial em suas vidas.

Em pesquisa realizada através do índice de entropia se propôs a avaliar o grau de heterogeneidade, desigualdades e diversidades nos processos de transição para a vida adulta comparando dois períodos de conjuntura econômica - o período que antecedeu a crise econômica na Espanha e os anos iniciais de saída da crise. A pesquisa concluiu que as diferenças não estão imbricadas aos períodos e sim relacionadas ao risco de pobreza dos jovens, com maior heterogeneidade entre aqueles que são mais pobres. Observou-se também a feminização da pobreza, pois as jovens apresentam menos possibilidades de acessar o mercado de trabalho, aliado a motivos culturais que acentuam a divisão de papeis entre moças e rapazes, associando ocupações de maior prestígio e recursos econômicos aos jovens (SÁNCHEZ-GALÁN, 2019).

Ainda tendo como mote as consequências derivadas da crise ocupacional, as análises realizadas por Borràs Català, Moreno Colom, Candela Soto e Legarreta Iza (2019) em suas pesquisas também identificam o papel chave que o gênero, as tradições culturais e a diversidade territorial exercem nas decisões, padrões, expectativas e práticas em relação aos itinerários formativos e ocupacionais dos jovens e das jovens.

Antônio Santos Ortega e Paz Martín Martín (2020) inovam suas análises ao relacionar os eventos que marcam a transição para a idade adulta na Espanha, o desemprego juvenil, as vidas precárias e as ações coletivas dos jovens em resposta à crise econômica. Concluem que, se antes havia entre os jovens certo conformismo ou sentimento de impotência frente às questões estruturais da crise, as mobilizações de 15 de maio de 2011 e seus desdobramentos romperam com a suposta aceitação. 
Dois estudos, um realizado em Portugal (KOVACS, 2013) e o outro na Espanha (GENTILE, 2015), foram sobre as trajetórias de inserção laboral de jovens de diferentes camadas sociais diante de contextos de flexibilização do mercado de trabalho. Os jovens portugueses, ao terminar o ensino básico, seguem realizando a transição laboral. Porém, aqueles com experiência profissional, que trabalharam durante o ensino básico, conseguem uma boa inserção, mesmo que o clima de incerteza ainda esteja presente; já os que não têm experiência anterior, acabam em inserções precárias. Na Espanha, Gentile estudou jovens com ensino superior e identificou três discursos deles frente às dificuldades encontradas com a crise: no primeiro, a crise é narrada como uma armadilha, em que os jovens não se sentiam donos de seus destinos e perderam seus pontos de referência para planejar o futuro; no segundo, a crise é entendida como um obstáculo, ou seja, os jovens reconhecem a gravidade da conjuntura econômica, mas se mantêm otimistas, pois estão envolvidos em projetos de emancipação coerentes com seus itinerários de formação; por fim, alguns jovens viam na crise uma oportunidade, pois são originários de famílias com alta disponibilidade econômica e patrimonial.

Compreender a transição para a vida adulta analisando as razões para constituir domicílio independentes, a parentalidade, alongamento da estadia na casa paterna, os apoios e relações familiares esteve presente em seis estudos. Pesquisas realizadas em países europeus do Sul, do Norte e do Oeste, na América do Norte e na Austrália aferiram que os jovens são motivados a sair do domicílio paterno por diversas situações, como trabalho, estudos, serviço militar, fuga dos conflitos familiares, casamento, independência, entre outras. $\mathrm{E}$ as formas de habitação podem ser divididas em duas: sair para morar sozinho ou para morar com companheiro romântico (MULDER, 2009). Pesquisas realizadas em países da Europa Ocidental e América do Norte (SWARTZ; O'BRIEN, 2009) identificaram que as famílias entendem o apoio material disponibilizado para seus filhos como andaimes em direção à maior independência. Pesquisa realizada na Holanda mostrou que, a despeito da despadronização do curso de vida, os jovens desejam seguir o caminho de transição para a vida adulta, que consiste em terminar os estudos, trabalhar, constituir habitação independente e se casar (DU BOIS-REYMOND, 2009).

Em estudo comparado entre Espanha, Itália, Portugal, Holanda, Luxemburgo, Bélgica, França, Alemanha, Grécia, Áustria e Reino Unido (MORENO, 2012), fatores como escassas políticas de emancipação, solidariedade intergeracional, cultura da casa própria, condição econômica precária do mercado de trabalho, juntamente com a inflexibilidade e o dispendioso mercado da habitação criaram uma cultura de dependência dos pais como estratégia de acúmulo de capital e uma estratégia para driblar os riscos em um ambiente precário exemplificado pela exclusão social e pobreza.

Estudo espanhol se debruçou no papel da família para a transição para a vida adulta de jovens que passaram parte da infância e adolescência em centro de proteção. A pesquisa inferiu que para que haja sucesso na transição é preciso que se tenha uma rede de apoio e que relações de interdependência sejam estabelecidas, como a criação de redes de apoio social com pessoas significativas na vida dos jovens. Quando atingem a maioridade os jovens precisam sair dos abrigos o que os leva a uma busca por uma residência permanente, o que não é nada fácil, ou no retorno para a casa da família de origem, que na maioria das vezes não está nos planos dos jovens (CUENCA PARIS; CAMPOS HERMANO; GOIG MARTÍNEZ, 2018).

Com menor incidência nos estudos, houve também o interesse por apreender como os apoios estatais impactavam na transição para a vida adulta. Nesse ponto, será dado destaque ao estudo realizado por Cécille Van de Velde (2008), autora que realizou pesquisa comparativa acerca das experiências contemporâneas de passagem para a idade adulta na Dinamarca, Reino Unido, França e Espanha.

Em sua pesquisa Van de Veld (2008) confrontou as noções de maturidade, responsabilidade, independência e as múltiplas referências: indentitária, familiares ou profissionais. A autora afirma que, em uma sociedade que valoriza a mobilidade e o vir a ser, a passagem para a vida adulta cada 
vez mais atende a uma representação de si, não sendo, portanto, mera aquisição estatutária. $\mathrm{O}$ reconhecimento intrafamiliar do status de adulto é mais valorizado entre os jovens. A autonomia e a responsabilidade, mais que a independência financeira, seriam características marcantes da idade adulta para os jovens pesquisados. Ao final da pesquisa, foram identificadas quatro formas de experiências de tornar-se adulto, que são tipologias de experiências e não categorização dos indivíduos: "se encontrar", "se assumir", "se colocar" e "se instalar".

A primeira tipologia, "se encontrar" ou a lógica do desenvolvimento pessoal, é uma característica da sociedade dinamarquesa. Nela, a juventude é institucionalizada, há um alto nível de proteção social garantido para todos os cidadãos. $\mathrm{O}$ auxílio estatal garante a independência financeira e permite aos jovens trilharem caminhos baseados na reversibilidade e na descontinuidade, em um processo de busca de si, de "se encontrar". A valorização da independência tem raízes na tradição protestante, presente na socialização empreendida pelos pais, sendo a autonomia o eixo condutor (VAN DE VELD, 2008).

Em "se assumir" ou a lógica da emancipação individual, enquadram-se os jovens britânicos. O percurso pauta-se em uma lógica de emancipação individual dividida em três fases: independência residencial, estudos e aquisição de um emprego estável. A estrutura social sustenta as trajetórias dos jovens, valorizando o emprego e culpabilizando o possível alongamento de apoio dos pais. Essa estrutura, do tipo liberal, configura os percursos dos jovens e define o que é ser adulto. A norma presente pauta-se no fato de que os jovens assumam os atributos sociais adultos, incentivando-os a ligeiramente provar suas capacidades individuais, dando sentido aos seus itinerários biográficos (VAN DE VELD, 2008).

A tipologia "se colocar" ou a lógica da integração social reporta-se aos jovens franceses, pois vivem sob pressão social, que lhes convida a "se colocar" no seio de uma hierarquia pré-definida. $\mathrm{Na}$ sociedade francesa, a idade adulta é vista como definitiva, sendo a juventude associada ao tempo de estudos e da inserção profissional. Os jovens da França vivem um paradoxo, em que lhes são exigidos comportamentos de independência, mas precisam trilhar trajetórias profissionais. Essas trajetórias duais inscrevem-se no tipo de sociedade corporativista, em que o status social define o indivíduo, cujo acesso está condicionado à obtenção de um diploma (VAN DE VELD, 2008).

Na tipologia "se instalar" ou a lógica da adesão familiar, estão os jovens espanhóis. Partir da casa dos pais para se inserir de fato na vida adulta está condicionado à obtenção de emprego, ter uma casa própria e ao casamento, o que ocorre cada vez mais tarde. Essa condição está apoiada em uma matriz cultural ligada ao catolicismo, que dá contornos a esse tipo de itinerário de instalação (VAN DE VELD, 2008).

Elina Lahelma e Toula Gordon (2008), em pesquisa realizada com jovens finlandeses, aferiram que o Estado de Bem-estar social finlandês disponibiliza recursos sociais e endossa, por meio de políticas públicas, a independência individual e autossuficiência dos jovens. No entanto, o aporte financeiro recebido pela família não pode ser descartado e este varia entre as diferentes classes sociais.

Valentina Cuzzocrea e Rebecca Collins (2015) utilizaram os resultados de estudo de caso transnacional, o projeto Edgeryders ${ }^{5}$, que disponibilizou uma plataforma on-line e convidou os participantes a debater suas experiências, na tentativa de alcançar uma idade adulta totalmente independente. Os jovens participantes do referido projeto enfrentavam os desafios, especialmente os relacionados ao setor produtivo, por meio de ações colaborativas, desenvolvendo projetos em suas comunidades, transformando os problemas socioeconômicos das regiões em que vivem, muitas vezes encarados como individuais, em problemas coletivos, buscando soluções que pudessem beneficiar a todos.

$5 \mathrm{O}$ estudo foi realizado pelo Conselho da Europa, que teve como objetivo explorar onde as políticas nacionais e transnacionais de juventude existentes não estavam fornecendo estruturas e mecanismos de apoio adequados para a transição dos jovens para a idade adulta independente. 
Na Espanha, Echaves García e Navarro Yañez (2018) relacionaram a emancipação da casa de origem e os apoios estatais existentes para a aquisição de habitação para compreender o retardamento dos jovens para sair da casa dos pais. A análise confirmou que a emancipação dos jovens depende, sobretudo, de seus atributos e/ou recursos individuais. Contudo, mesmo que os efeitos sejam bastante reduzidos em comparação aos fatores individuais, o regime de aquisição de habitação parece atuar como uma estrutura de oportunidade que facilita, ou inibe, o processo de saída da casa de origem.

Pesquisa portuguesa, reexaminou as transições para a idade adulta de três coortes portuguesas (nascidas em 1935-1940, 1950-1955 e 1970-1975), nomeadamente no que diz respeito ao seu tempo, duração e sequência. No que diz respeito ao término dos estudos e inserção no mercado do trabalho a pesquisa inferiu que nas coortes mais recentes ocorrem mais tarde. A idade média de saída da casa dos pais nas diferentes coortes ocorre aproximadamente na mesma idade. Outro dado observado foi o intervalo entre a idade em que os jovens começaram a trabalhar e saíram da casa dos pais, a pesquisa mostrou que esses eventos não eram, em sua maioria, sincronizados, contestando a noção propagada de que, no passado, a conquista da autonomia residencial ocorria logo após a inserção laboral (RAMOS, 2018).

Outro estudo realizado em Portugal examinou o impacto da educação pré-escolar em diversos aspectos da vida dos jovens adultos. Direcionou esforços para alguns domínios, como desempenho acadêmico e profissional, problemas de saúde mental e delinquência, número de amigos e sentimento de bem-estar geral. No que diz respeito ao desempenho acadêmico e profissional dos jovens participantes, observou-se que o grupo com educação pré-escolar tinha, em média, concluído mais anos de escolaridade, sofrera menos repetências ao longo do seu percurso académico e participava em mais atividades culturais do que os seus pares sem educação pré-escolar (FONSECA, 2019).

Por fim, Francisco Javier Sánchez Galán (2020), realizou análise cruzada entre os eventos que marcam os processos de transição e os fatores considerados relevantes nessa movimentação, como idade, sexo, término dos estudos, risco de pobreza, conjuntura econômica e tipo de residência em que reside. A análise combinada mostrou que nos períodos de crise econômica e de difícil acesso ao mercado de trabalho os jovens, em sua maioria as mulheres, tendem a prolongar o período formativo, "atrasando" a transição escolar. O fator família é preponderante na possibilidade de seguir estudando e na inserção laboral, contudo, o risco de pobreza encurta a transição residencial, isto é, aqueles que vêm de famílias pobres têm maior probabilidade de saírem da casa dos pais.

\section{As pesquisas latino-americanas}

Os estudos realizados na América Latina são mais recentes que os do Hemisfério Norte, com uma produção relativamente menor na primeira década dos anos 2000, ampliada na segunda década. No que foi possível localizar durante a revisão bibliográfica efetuada, observou-se que são poucos os países latinos dedicados ao tema nas áreas das Ciência Sociais e Educação. Os países que mais realizaram pesquisas foram México e Argentina, e, em menor proporção, Uruguai, Cuba e Chile. Ao todo 16 estudos foram mapeados.

Assim como nos países do Hemisfério Norte, estudos realizados na América Latina buscaram compreender a não sincronização das etapas de transição para a vida adulta, a fim de verificar se o fenômeno, intitulado como prolongamento da juventude também estava presente em seus países e como ele se expressava entre os jovens de diferentes camadas sociais. Foram estudos apoiados em dados estatísticos de censo demográficos ou de pesquisas sobre juventude, comparando diversas cortes de jovens.

Os estudos sobre a transição escola-trabalho também estiveram presentes e, a partir da segunda metade dos anos 2000, as pesquisas elegeram públicos específicos. Desse modo, duas investigações visaram compreender como os jovens, moradores de zonas rurais, transitavam para 
a vida adulta. A primeira, realizada no México, identificou que os jovens residentes em municípios de economia rural casam-se mais cedo e deixam a escola para inserirem-se no mercado de trabalho, encontrando dificuldades para conseguir um emprego mais qualificado (PEREZ, 2012). A segunda pesquisa, realizada na Argentina, mostrou que as principais dificuldades encontradas para que os jovens transitem para a idade adulta é o acesso à terra e a tensão geracional. Esses empecilhos levam os jovens a migrarem para os grandes centros urbanos em busca de trabalho (DIEZ, 2014).

Quatro pesquisas tiveram como objetivo compreender como os jovens em situação de desvantagem social e moradores das zonas urbanas estavam transitando para a idade adulta. Pesquisa realizada na Argentina estudou jovens participantes de organizações de qualificação profissional e inferiu que essas organizações atuavam como mediadoras de capital social e forneciam suportes coletivos, que contribuíam para que os jovens desenvolvessem suas próprias estratégias de ação no trânsito para a vida adulta (JACINTO; MILLENAAR, 2009). Em pesquisa comparativa entre estudantes de escolas públicas e privadas de La Plata e Buenos Aires, foram identificados dois caminhos seguidos por eles: ou ingressam no ensino superior, adiando a entrada no mercado de trabalho, ou aliam as atividades laborais com os estudos superiores (OTERO, 2011).

Estudo mexicano reconstruiu trajetórias de jovens em situação de vulnerabilidade e identificou que alguns jovens superavam as desvantagens por meio da escolarização e da inserção laboral e outros acabavam reproduzindo as desvantagens, inserindo-se em trabalhos precários (MORA SALAS; OLIVEIRA, 2014). Outro estudo, também mexicano, investigou como jovens que não estudavam e não trabalhavam realizavam o movimento em direção à vida adulta. Identificou que alguns permaneciam na casa dos pais com ou sem filhos, sem realizar nenhuma transição (BERMUDEZ-LOBERA, 2015).

Duas pesquisas interessaram-se pelas trajetórias percorridas por jovens que tiveram filhos durante a adolescência. Estudo uruguaio identificou que as jovens mães, em comparação com as que não tinham filhos, acabavam deixando a escola, enfrentavam dificuldades para a inserção laboral e para constituir domicílio independente dos pais (VARELA; LARA, 2015). Pesquisa mexicana comparou estudantes universitárias mães e não mães, a fim de compreender as trajetórias percorridas por aquelas que tiveram filhos antes de ingressar no ensino superior e por aquelas que tiveram filhos durante. Identificou que as mães estudantes que tiveram filhos durante o curso encontravam dificuldades para permanecer na universidade (MILLER; ARVIZU, 2016).

A compreensão das relações familiares e emancipação habitacional também foram objetos de estudo em alguns países. As configurações familiares e o modo como os jovens encarregavam-se das dinâmicas domésticas, redefinindo os papéis assumidos no interior do domicílio de origem e adquirindo maior autonomia frente ao mundo adulto, foi objeto de estudo mexicano (MORA SALAS; OLIVEIRA, 2009). A emancipação familiar e os apoios recebidos (estatais, para jovens em desvantagem social; e familiar, para os de famílias de classe média) foram tema de pesquisa na Argentina (ARANCIBIA, 2013). No Uruguai, observou-se que quanto maior o grau de escolaridades dos jovens, mais tempo permanecem na casa dos pais. Constatou-se também que os jovens, ao saírem da casa dos pais, estavam formando menos domicílios familiares, ou seja, o número de casas compartilhadas com amigos havia aumentado (CIGANDA; PARDO, 2014).

Pesquisa com jovens moradores de Buenos Aires analisou as decisões econômicas sobre a moradia e como elas se apresentam em diferentes gerações. Os resultados da pesquisa mostram que os jovens dessa geração veem o aluguel de habitação como possibilidade para sair da casa dos pais, porém são questionados por seus pais que avaliam que o aluguel é uma "perda" de dinheiro e buscam convencê-los a permanecer em casa até que tenham condições de adquirir propriedade (FELICE, 2017).

Roberti (2017) ao reconstruir as trajetórias de jovens argentinos moradores em um bairro periférico analisou a ruptura do modelo linear de transição à vida adulta. A pesquisa identificou uma diversidade de trajetórias que atualmente os jovens vivenciam entre o término dos estudos, a inserção laboral e os padrões de formação de família. Essa diversidade ressaltou o quão são múltiplas e desiguais as formas de viver a juventude. 
No México, estudo realizado por Martinez Salgado e Tapia-Mcclung (2017), identificou que independente da região em que os jovens moram, o número de mulheres unidas é maior que a dos homens em todos os grupos de idade. No que diz respeito ao número de nascimentos, os dados demonstram que em metade dos municípios mexicanos o nível de nascimentos varia entre 35,7\% e 53\%. Esse indicador mostra um elevado grau de correlação espacial, ou seja, existe uma alta concentração de municípios com níveis de nascimento semelhantes. A correlação também está presente quando se analisa o número de jovens com o ensino secundário completo, apenas $60 \%$ concluem essa etapa de ensino.

Durante a revisão bibliográfica foi localizado estudo comparativo entre as capitais mexicana e argentina, a fim de comparar semelhanças e diferenças no trânsito para a vida adulta entre os jovens de ambos os países. Foram analisadas as clássicas etapas utilizadas para compreender a transição e identificou-se que os jovens mexicanos deixavam a escola mais cedo que os portenhos, que prosseguiam nos estudos e acessavam mais o ensino superior (FERRARIS; SALGADO, 2015).

Estudo chileno estudou as contribuições dos Projetos de Vida e as oportunidades do ensino médio para os processos de transição para a idade adulta. A pesquisa inferiu que, para grandes contingentes da população, a educação básica não é mais o ponto central para a transição até o mundo do trabalho. Os projetos de vida dos jovens estudados mostram que existem inúmeras transições que se concentram no âmbito educativo, como a entrada em distintas instituições de ensino superior, a escolha de uma carreira, os possíveis estudos de pós-graduação ou a busca por especializações, são também rituais de transição até a idade adulta (PUGA RAYO et al., 2017).

Dina Krauskopf-Roger (2019) em sua pesquisa com estudantes de diferentes regiões do Chile, analisou as relações intergeracionais, emancipação e independência. Concluiu que um grupo importante de jovens desenvolveu novas formas de abordar as relações intergeracionais, os processos de individualização e independência. Para os jovens entrevistados, sair da casa dos pais com capacidade de se manterem por si mesmos é fundamental para que ocorra a emancipação familiar. Desse modo, a prioridade não é sair e sim encontrar trabalho. Os jovens com menor capital econômico e cultural são os que mais vislumbram a vida adulta. Esse anseio reflete as pressões sociais e as exigências familiares, o que dificulta a construção pelos próprios jovens de uma visão própria sobre seus processos de transição.

As pesquisas aqui revisadas trouxeram pistas de como os estudos sobre transição para a vida adulta entraram na agenda de alguns países latino-americanos. Assim como observado no Hemisfério Norte, as análises concentram-se no tema da inserção laboral e há poucas pesquisas comparativas entre os países, o que não permite delinear aproximações e diferenças nos modos de entrar na vida adulta dos jovens dos diferentes países. É, portanto, ainda um tema emergente, com poucas produções em outros países.

\section{A construção de uma agenda de pesquisa brasileira sobre o tema da transição para a idade adulta ${ }^{6}$}

Os estudos sobre as condições de vida de homens e mulheres jovens intensificaram-se nos anos 1990 no Brasil. O mote inicial para tal enfoque foi o temor de uma explosão demográfica, uma vez que o potencial de reprodução dos jovens havia se acentuado. Ainda relacionado à fecundidade, as pesquisas focaram na maternidade entre as jovens com idade abaixo de 20 anos. Outros temas também nortearam as investigações sobre juventude, mas mantiveram a discussão pautada pelo negativismo, "relacionadas à instabilidade derivada das mudanças no mercado de trabalho, da violência das grandes cidades e das crescentes taxas de prevalência e de mortalidade por difusão de doenças sexualmente transmissíveis" (CAMARANO; MELLO; PASINATO; KANSO, 2004, p. 15). 
No Brasil, a questão da transição para a vida adulta não se tornou objeto privilegiado de investigação nas áreas da Ciências Sociais e Educação. Um número significativo de trabalhos, que direta ou indiretamente se debruçaram sobre o tema, foram realizados no âmbito da demografia e da economia, e raramente, no da sociologia e educação. (CAMARANO; MELLO; PASINATO; KANSO, 2004; CAMARANO, 2006; NASCIMENTO, 2006; VIEIRA, 2009; MADEIRA, 2009; MELLO, 2015; RIBEIRO, 2014). Do conjunto das pesquisas que analisaram os dados estatísticos para compreender a transição para a idade adulta, as seguintes serão destacadas: as coordenadas por Ana Amélia Camarano $(2004,2006)$ e a realizada por Joice Melo de Vieira (2009).

Em 2004, apoiando-se em dados das Pesquisas por Amostra de Domicílios (PNAD) do IBGE de 1982 e 2002, foi realizada a pesquisa demográfica Caminhos para a vida adulta: as múltiplas trajetórias dos jovens brasileiros. Os resultados trouxeram algumas indagações, como a seguinte: “Os jovens que não saem da casa parental tornam-se adultos?". Embora os dados disponíveis não tenham permitido responder tal indagação, as pesquisadoras salientaram a necessidade de reconhecer que o processo de se tornar adulto não depende apenas da passagem por determinadas etapas da vida, mas que é necessária a identificação do jovem com a idade adulta. A pesquisa mostrou que são múltiplos os trajetos percorridos pelos jovens nessa transição: alguns se tornam independentes, saindo da casa dos pais em condições de chefes e cônjuges; outros permanecem na condição de filhos por mais tempo na casa paterna. Em algumas situações, os filhos nascem antes do casamento, o casamento ocorre antes da inserção no mercado de trabalho, e assim por diante. A transição pode ocorrer em novos arranjos familiares, que não passem necessariamente pela saída da casa dos pais (CAMARANO; MELLO; PASINATO; KANSO, 2004).

No livro Transições para vida adulta ou vida adulta em transição, Camarano (2006) e demais pesquisadores identificaram que muitas das mudanças ocorridas na sociedade não dizem respeito apenas à população jovem, pois a instabilidade, geralmente associada ao período da juventude, também chegou à fase adulta. Para os autores, o alongamento da duração da vida foi a mudança mais importante aferida no período analisado, sendo que a redução da mortalidade infantil pode ser considerada a principal responsável. No intervalo de vinte anos, a pesquisa mostrou que as principais fases do curso de vida - infância, vida adulta e velhice - permanecem marcadas pelos mesmos eventos - término dos estudos, inserção laboral, formação de domicílio independente e parentalidade -, e a sequência delas permanece praticamente sem alteração: por exemplo, para os homens são os eventos relacionados ao mercado de trabalho que delimitam essas fases; já para as mulheres, o casamento e a maternidade ainda definem a vida adulta, embora a participação delas no mercado de trabalho tenha aumentado.

A pesquisa realizada por Joice Melo de Vieira (2009) possui como diferencial a metodologia adotada, que é a análise de entropia de combinação de status de coortes sintéticas ${ }^{7}$. Em sua tese de doutorado, identificou que o período mais intenso de mudança nos processos de transição aconteceu nos anos 2000, em São Paulo, em idades próximas das que ocorriam em 1970. Contudo, o nível da curva eleva-se mais em 2000 a partir dos 17 anos para ambos os sexos, o que indica que o curso de vida a partir dessa idade apresenta maior variabilidade, isto é, aumentaram as possibilidades de combinações de status.

No que diz respeito ao status laboral, tanto em 1970 como em 2000, no caso dos homens, havia maior heterogeneidade antes dos 20 anos e após os 40 anos, isto é, menos homens integrando a População Economicamente Ativa (PEA); entre os 20 e 40 anos, existia uma padronização,

7 Essa metodologia possibilita "medir a despadronização do curso de vida, o quão fragmentado se encontra um grupo em termos das experiências a que estão expostos, considerando o status escolar, laboral, residencial, marital e parental. [...] A amplitude do índice de entropia geral varia de 0 , quando há perfeita homogeneidade (ou seja, todos os indivíduos estariam concentrados em uma única combinação de status) até a entropia máxima (máxima heterogeneidade, situação na qual haveria exatamente o mesmo número de indivíduos em cada uma das combinações de status possíveis). O valor máximo da entropia depende de quantos status estão sendo combinados, já que no cálculo da entropia máxima é preciso conhecer o número total de combinações de status possíveis" (VIEIRA, 2009, p. 96 e 109). 
pois, participar da PEA é uma experiência universal para os rapazes. Já entre as mulheres, havia heterogeneidades em todas as idades na vida ativa, pois, ainda que a participação feminina tenha aumentado, ela ainda está longe de se tornar universal. A pesquisa captou também mudanças na autonomia residencial, principalmente entre os homens. Enquanto em 1970 a maioria absoluta havia conquistado autonomia residencial entre as idades de 25 e 39 anos, em 2000 houve uma diminuição de homens não residentes na casa dos pais. A porcentagem de homens e mulheres, chefes de família ou cônjuges em um domicílio independente, também diminuiu (p. 119).

Por fim, ao analisar as transições não familiares, Vieira observou que as idades de saída da escola e entrada no mercado de trabalho se sobrepuseram para a população jovem de 15-30 anos. Enquanto em 1970 as idades em que os rapazes pararam de estudar coincidiam com as idades em que se encontravam trabalhando, em 2000 o tempo escolar e o de trabalho passaram a ser conjugados. Entre as mulheres, não houve alterações neste aspecto. Nas transições familiares, os resultados revelaram que as mudanças não foram significativas, pois a idade em que se conquista a independência residencial ocorre muito próximo da idade em que os jovens se unem. Em relação à maternidade, a desigualdade de renda acentuou-se entre 1970 e 2000, isto é, em 2000 houve um rejuvenescimento da maternidade entre as moças mais pobres, e entre as ricas, $o$ adiamento.

Dentre as pesquisas qualitativas realizadas no Brasil, destaca-se o doutorado de Melissa Mattos Pimenta (2007), que compreendeu qual o papel dos sujeitos jovens na construção de seus trajetos biográficos. A pesquisa constatou que não há uma representação única de adulto e nem única de jovem, sendo as representações múltiplas e situadas segundo gênero e origem social. A partir de uma análise comparativa identificou que "nem todos os jovens passam pelas mesmas etapas de transição e, tampouco, as atravessam da mesma forma" (p. 392). No que diz respeito à escolarização e ao trabalho, os resultados obtidos evidenciaram que, embora a partir de 1990 tenha aumentado o número de crianças e adolescentes no sistema educativo, duas características permaneciam presentes e determinavam a relação entre escola e trabalho: o ingresso precoce na vida ativa e a conciliação ou superposição de estudo e trabalho.

Em relação aos estudos, o aspecto mais relevante encontrado, e que esteve presente na fala de todos os jovens dos diferentes segmentos sociais, foi a ideia de que a formação escolar é um processo de preparação para uma vida profissional, não sendo possível compreender essa dimensão desatrelada do universo do trabalho. A pesquisa revelou que, mesmo para os jovens que completaram o ensino superior e conseguiram ocupações mais qualificadas e melhor remuneradas, suas trajetórias profissionais foram marcadas por descontinuidades e irregularidades, assim como as dos jovens que não possuem ensino superior (PIMENTA, 2007).

Ao analisar o papel da família no processo de transição, Pimenta (2007) identificou que ela é mais que uma fonte de apoio material e financeiro: atua como facilitadora e mediadora da autonomização dos indivíduos. No entanto, os apoios materiais são importantes e, nos segmentos com maior capital econômico, a oferta é maior e pode se estender independentemente de limites de idade ou do fato de os jovens já não morarem mais com sua família.

As pesquisas destacadas oferecem um panorama de como foi construída a agenda brasileira de pesquisas sobre o tema da transição para a idade adulta. O levantamento bibliográfico localizou outros estudos qualitativos sobre o tema, que serão rapidamente abordados abaixo.

A maioria dos estudos aqui revisados, assim como pode ser identificado nas investigações realizadas no Hemisfério Norte e nos países latino-americanos, concentraram esforços para compreender como as mudanças ocorridas no mercado de trabalho afetaram a transição da escola para o universo laboral, elegendo-se públicos específicos para a análise.

Dois estudos realizados no Município de São Gonçalo (RJ) identificaram que os trajetos percorridos não são lineares, pois a região de moradia e a renda dos jovens interferem nas trajetórias. Os jovens moradores de regiões mais providas de equipamentos e serviços públicos, e que possuíam mais renda, articulavam experiências de trabalho com cursos de formação, o que lhes 
permitiu configurar uma área de atuação profissional. Os jovens residentes de regiões desprovidas de serviços e equipamentos públicos, e com rendas mais baixas, estudaram no período noturno e tinham histórico de repetência, com experiências de trabalho reduzidas e restritas, realizando trabalhos manuais e domésticos (PEREGRINO, 2011; FERNANDEZ, 2012).

Em Belo Horizonte, a pesquisa analisou as trajetórias de dois jovens moradores de bairros periféricos e identificou que os caminhos percorridos por eles foram marcados pela precariedade, incerteza e necessidade de escolher entre entrar para o tráfico ou buscar um trabalho fora da ilegalidade. Para estes jovens, o sistema educativo ofereceu pouco ou nenhum subsídio que os auxiliassem no caminho que trilharam para a vida adulta (MARINHO, 2015).

Em pesquisa realizada com jovens concluintes do ensino médio, moradores de um distrito rural de Feira de Santana (BA), constatou-se que os jovens vivem dois momentos de transição: terminar o ensino médio e mudar-se da área rural para a urbana, onde estão as opções de trabalho fora da área agrícola. Encontram-se em um dilema, pois nem todos querem deixar a área rural, mas migrar é para muitos a condição para manter a família no campo. (LARANJEIRA; IRIART; RODRIGUES, 2016).

Estudo realizado com jovens de camadas médias e concluintes do ensino superior no Rio de Janeiro identificou que eles apostavam na ampliação da escolarização para ascender profissional e socialmente. Subjacente ao ingresso no ensino superior estava o projeto de independência e autonomia em relação à família; porém, diante da conjuntura econômica, questionavam a viabilidade de concretizá-lo (BARROS, 2010).

No levantamento realizado foi encontrada somente uma pesquisa brasileira que estudou o tema da transição para a idade adulta visando compreender os novos arranjos familiares e como se configuram a independência econômica e a autonomia dos jovens. Nádia Maciel Falcão (2015), ao estudar jovens moradores de Manaus, identificou que, embora as relações entre pais e filhos tenham se tornado cada vez mais espaços de negociação e aconselhamento, há uma estreita relação entre independência econômica e ampliação de autonomia. Mas a conquista da autonomia é influenciada por outros fatores, em especial pelo entendimento dos jovens de que a casa é de seus pais e que devem respeitar as regras por eles impostas, mesmo quando eles são responsáveis pela manutenção financeira da família (FALCÃO, 2014, 2015).

Dois estudos analisaram a transição para a idade adulta a partir da percepção dos jovens sobre os sentidos de ser adulto. Pesquisa realizada com jovens recifenses mostrou que o entendimento dos participantes é de que a responsabilidade é algo que acompanha o indivíduo a vida inteira e que a maturidade é diferente de ser adulto, pois é o que se aprende por meio das experiências. Quanto à noção de transição, para os entrevistados a própria vida é uma transição, ou seja, a cada momento do percurso que ocorrem mudanças, novos desafios aparecem (MULLER, 2008). Em estudo comparativo entre Brasil e Espanha, identificou-se que, diferente dos jovens espanhóis, os brasileiros não viam contradição em manter uma identidade jovem, ainda que já tivessem cruzado alguns limiares da vida adulta. Somente os jovens com filhos identificavam-se como adultos (NASCIMENTO; ALVARO, 2014).

Por fim, pesquisa realizada com jovens migrantes haitianos moradores de São Paulo mostrou que a migração para esses jovens passou a compor mais um momento a ser enfrentado para se tornar adulto. Mesmo para os jovens que vieram para o Brasil após o terremoto ocorrido em 2010, deixar o país já estava em seus planos, pois as condições econômicas não eram favoráveis (BAPTISTE, 2015).

\section{Conclusões}

Importante reiterar que a revisão bibliográfica realizada não foi exaustiva. O objetivo foi identificar os motivos iniciais que levaram os pesquisadores a estudar a transição para a vida adulta, as contribuições trazidas por eles e quais os principais temas mais presentes nas investigações. Dessa forma, a revisão salientou que, a partir do momento em que a transição dos jovens 
para a vida adulta tornou-se objeto de preocupação de diferentes áreas de pesquisa, a transição escola-trabalho configurou-se como um dos principais recortes realizados para compreender as mudanças ocorridas para tornar-se adulto, seguida da constituição de um domicílio próprio, matrimônio e chegada dos filhos.

O interesse pela transição escola-trabalho pode ser explicado pelo fato de a inserção laboral não ser mais apenas um dos momentos da transição para a idade adulta, mas sim um longo processo que tem como objetivo a obtenção de um emprego mais estável. Além disso, a maioria das pesquisas sobre juventude busca compreender os jovens na intersecção com a escola, com o trabalho ou unem essas duas dimensões. Haveria, portanto, uma transposição dessas temáticas para os estudos sobre transição.

A revisão apresenta algumas perspectivas para a realização de novos estudos sobre o tema no Brasil, ampliando assim o entendimento sobre a juventude e os processos que seguem para inserir-se na vida adulta. Os estudos apontam que as trajetórias não são lineares, porém, é preciso estudos que tenham como ponto central as desigualdades raciais, de gênero e territoriais que possibilitem aferir como essas desigualdades afetam a transição de moças e rapazes para a vida adulta.

Também são necessárias pesquisas que levem em consideração outros aspectos da vida dos jovens e que também afetam os modos dos jovens transitar até a vida adulta, como, por exemplo, o tempo livre, a participação política, a atuação coletiva, a religião, entre outros. Por fim, existe uma lacuna imensa nos estudos brasileiros sobre os apoios estatais voltados aos jovens para que possam trilhar o caminho até a vida adulta. Esse se configura como um campo profícuo de pesquisas sobre transição.

\section{Referências}

ALCAIDE, Izaskun Artegui. El impacto de la incertidumbre en la transición a la edad adulta: Posiciones biográficas y consecuencias sobre la vida. Arbor-ciencia Pensamiento Y Cultura, Espanha, v. 193, n. 784, abr./jun. 2017. Disponível em: https://dialnet.unirioja.es/servlet/articulo?codigo=6123258. Acesso em: 15 dez. 2020.

ARANCIBIA, Milena. Trayectorias habitacionales de lãs y los jóvenes: construir un hogar propio en el área metropolitana de Buenos Aires entre 1999 y 2013. Última Década, Santiago, n. 44, p. 171-193, 2016.

BARROS, Myriam Moraes Lins de. Trajetórias de jovens adultos: ciclo de vida e mobilidade social. Horizontes Antropológicos, Porto Alegre, v. 16, n. 34, p. 71-92, jul./dez. 2010. Disponível em: https://doi.org/10.1590/S0104-71832010000200004. Acesso em: 11 set. 2017.

BAPTISTE, Chandeline Jean. Transição para a vida adulta e migração internacional: o caso dos jovens haitianos na cidade de São Paulo. 2015. Dissertação (Mestrado em Demografia) - Universidade Estadual de Campinas, Campinas, 2015.

BERMUDEZ-LOBERA, Juan. Las transiciones a la adultez de los jóvenes que no estudian ni trabajan (ninis) en México. Papeles de Población, Toluca, n. 79, p. 243-279, 2014.

BORRÀS CATALÀ, Vicent; MORENO COLOM, Sara; CANDELA SOTO, Paloma; LEGARRETA IZA, Matxalen. Jóvenes en perpetuo tránsito hacia ninguna parte. Revista Española de Sociología, Barcelona, v. 28, n. 2, p. 365-380, 30 abr. 2019. Disponível em: https://recyt.fecyt.es/index.php/res/article/view/64360/43771. Acesso em: 15 dez. 2020.

CAMARANO, Ana Amélia (org.). Transição para a vida adulta ou vida adulta em transição? Rio de Janeiro: IPEA, 2006.

CAMARANO, Ana Amélia; MELlO, Juliana L.; PASINATO, Maria Tereza; KANSO, Solange. Caminhos para a vida adulta: as múltiplas trajetórias dos jovens brasileiros. Rio de Janeiro: IPEA, 2004.

CASAL, Joaquim; MERINO, Rafael; GARCIA, Maribel. Pasado y futuro del estudio sobre la transición de los jóvenes. Papers Sociologia, Barcelona, v. 96, n. 4, p. 1139-1162, 2011.

CIGANDA, Daniel; PARDO, Ignacio. Emancipación y formación de hogares entre los jóvenes uruguayos: las transformaciones recientes. Papeles de Población, Toluca, n. 82, p. 203-231, 2014. 
COMASÒLIVAS MOYA, Antonio; SALA-ROCA, Josefina; MARZO ARPÓN, Teresa Eulàlia. Los recursos residenciales para la transición hacia la vida adulta de los jóvenes tutelados em Cataluña. Pedagogía Social: revista interuniversitaria, Espanha, n. 31, p. 125-137, 2018.

CUENCA PARIS, M. Elena; CAMPOS HERNANDO, Gema; GOIG MARTÍNEZ, Rosa M.. El tránsito a la vida adulta de los jóvenes en acogimiento residencial: el rol de la familia. Educación XX1, Madrid, v. 21, n. 1, p. 321-344, nov. 2018. Disponível em: http://revistas.uned.es/index.php/educacionXX1/article/view/20201. Acesso em: 20 dez. 2020.

CUZZOCREA, Valentina; COLLINS, Rebecca. Collaborative individualization? Peer-to-peer action in youth transitions. Young, [s. l.], v. 23, n. 2, p. 136-153, 2015.

DIEZ, Valeria B. Gili. El proceso de transición a la vida adulta de jóvenes rurales sanjuaninos. Kairos, São Paulo, ano 18, n. 33, p. 1-15, 2014. Disponível em: http://www.revistakairos.org. Acesso em: 11 set. 2018.

DU BOIS-REYMOND, Manuela; BLASCO, Andreu. Transiciones tipo yo-yo y trajectorias fallidas: hacia las políticas integradas de transición para los jóvenes europeos. Revista Estudios de Juventud, Madrid, v. 65, n. 04, p. 11-29, 2004.

DU BOIS-REYMOND, Manuela. Young parenthood in the Netherlands. Young, [s.l.], v. 17, n. 3, p. 265-283, 2009.

ECHAVES GARCÍA, Antonio; NAVARRO YAÑEZ, Clemente Jesús. Regímenes de provisión de vivienda y emancipación residencial: análisis del esfuerzo público en vivienda en España y efecto en las oportunidades de emancipación desde una perspectiva autonómica comparada. Política y Sociedad, Madrid, v. 55, n. 2, p. 615-638, 2018.

EGRIS - European Group For Integrated Social Research. Misleanding Trajectories: transition dilemmas of young adults in Europe. Journal of Youth Studies, [s. l.], v. 4, n. 1, p. 101-118, 2001.

ESTEFANÍA, Miguel Melendro. El tránsito a la vida adulta de los jóvenes en dificultad social. Ekaina, Madrid, n. 49, p. 93-106, jun. 2011.

FALCÃO, Nádia Maciel. Possibilidades de compreensão da transição para a vida adulta na atualidade. In: REUNIÃO NACIONAL DA ANPED, 37., 2015, Florianópolis. Anais [...]. Florianópolis: UFSC, 2015. Disponível em: http://37reuniao.anped.org.br/wp-content/uploads/2015/02/Trabalho-GT03-4340.pdf. Acesso em: 11 set. 2018.

FALCÃO, Nádia Maciel. "É pesado, mas vou levando": jovens de Manaus entre a escola e o trabalho. 2014. Tese (Doutorado em Educação) - Universidade Federal Fluminense, Niterói, 2014.

FANZERES, Luis; CRUZ-SANTOS, Anabela; SANTOS, Sofia. A transição para a idade adulta dos alunos com NEE: percepções dos profissionais. Journal of Research in Special Educational Needs, [s. l.], v. 16, n. 1, p. 1050-1054, 2016.

FELICE, Magdalena. "Invertir en vida": decisiones económicas y diferencias generacionales en torno a la vivienda en jóvenes de la ciudad de Buenos Aires, Argentina. Antípoda: Revista de Antropología y Arqueología, Bogotá, n. 28, p. 193-212, mayo/agosto 2017. Disponível em: http://www.scielo.org.co/scielo.php?script=sci_arttext\&pi$\mathrm{d}=$ S1900-54072017000200193\&lng=en\&nrm=iso. Acesso em: 05 jan. 2021.

FERNANDEZ, Aline da Fonseca. Efeitos do território sobre processos de transição para a vida adulta: estudo de caso do Município de São Gonçalo. 2012. Dissertação (Mestrado em Educação, Cultura e Comunicação) - Universidade do Estado do Rio de Janeiro, Rio de Janeiro, 2012.

FERRARIS, Sabrina A.; SALGADO, Mario Martínez. Entre la escuela y el trabajo. El tránsito a la vida adulta de los jóvenes en la Ciudad de Buenos Aires y el Distrito Federal. Estudios Demográficos y Urbano, Ciudad de México, v. 30, n. 2, p. 405-431, 2015.

FONAYET, Francesc Valls. El impacto de la crisis entre los jóvenes en España. Revista de Estudios Sociológicos, Ciudad de México, n. 54, p. 134-149, 2015.

FONSECA, António Castro. Importância da Educação Pré-Escolar na Transição para a Idade Adulta: Resultados de um Estudo Português. Revista Portuguesa de Pedagogia, Coimbra, v. 52, n. 2, p. 89-109, 2019. DOI: 10.14195/16478614_52-2_5. Disponível em: https://impactum-journals.uc.pt/rppedagogia/article/view/1647-8614_52-2_5. Acesso em: 05 jan. 2021.

GALLAND, Olivier. L’entrée des jeunes dans la vie adulte. Problèmes Politiques et Sociaux, Paris, n. 794, dez. 1997.

GALLAND, Olivier. Un nouvel age de la vie? Revue Française de Sociologie, Paris, v. 31, n. 4, p. 529-551, 1990.

GENTILE, Alessandro. Jóvenes titulados superiores en la encrucijada de la crisis. RECERCA: Revista de Pensament I Analise, Castellón de la Plana, n. 16, p. 35-58, 2015.

GOYETTE, Martin. Dinámicas relacionales de las transiciones a la vida adulta. Complementariedad entre redes, apoyos e soportes. REDES: Revista Hispana para la análisis de redes sociales, Barcelona, v. 18, n. 4, 2010.

JACINTO, Claudia; MILLENAAR, Verónica. Enfoques de programas para la inclusión laboral de los jóvenes pobres: lo institucional como soporte subjetivo. Última Década, Santiago, v. 17, n. 30, p. 67-92, 2009.

KOVÁCS, Ilona. Flexibilização do mercado de trabalho e percursos de transição de jovens: uma abordagem qualitativa do caso da área metropolitana de Lisboa. SOCIUS Working Papers, Lisboa, n. 1, p. 1-39, 2013. 
KRAUSKOPF-ROGER, Dina. Relaciones intergeneracionales, emancipación e independencia de jóvenes estudiantes chilenos. Revista latinoamericana de ciencias sociales, niñez y juventud, Manizales, v. 17, n. 1, p. 75-87, 2019. Disponível em: http://www.codajic.org/sites/www.codajic.org/files/Relaciones\%20intergeneracionales,\%20emancipaci\%C3\%B3n\%20e\%20independencia\%20de\%20j\%C3\%B3venes\%20estudiantes\%20chilenos.pdf. Acesso em: 12 dez. 2020.

LAHELMA, Elina; GORDON, Toula. Resources and (in(ter))dependence young people's reflections on parente. Young, [s.l.], v. 16, n. 2, p. 209-226, 2008

LARANJEIRA, Denise Helena Pereira; IRIART, Mirela Figueiredo Santos; RODRIGUES, Milena Santos. Problematizando as transições juvenis na saída do Ensino Médio. Educação \& Realidade, Porto Alegre, v. 41, n. 1, p. 117-133, 2016. Disponível em: https://www.scielo.br/j/edreal/a/jGCsfypH7w4gJcPwF7C7sfh/?lang=pt. Acesso em: 13 nov. 2016.

LIMA, Telma Cristiane Sasso de; MIOTO, Regina Célia Tamaso. Procedimentos metodológicos na construção do conhecimento científico: a pesquisa bibliográfica. Revista katálysis, Florianópolis, v. 10, n. especial, p. 37-45, 2007.

MADEIRA, Fátima de Carvalho. Transição para a vida adulta no Brasil: etapas e contextos a partir das PNADs de 1955 a 2005. 2009. Dissertação (Mestrado em Estudos Populacionais e Pesquisas Sociais) - Escola Nacional de Ciências Estatísticas, Rio de Janeiro, 2009.

MARINHO, Marco. Transição para a vida adulta e práticas culturais na periferia metropolitana de Belo Horizonte: as trajetórias de Miro e Faro. Fórum sociológico, Lisboa, n. 26, 2015. Disponível em: https://journals.openedition.org/ sociologico/1195. Acesso em: 15 nov. 2017.

MARTINEZ SALGADO, Mario; TAPIA-MCCLUNG, Rodrigo. Variación espacial de la unión conyugal de los jóvenes en México. Estudios demográficos urbanos, México, v. 32, n. 1, p. 131-161, enero/abr. 2017. Disponível em: http://www. scielo.org.mx/scielo.php?script=sci_arttext\&pid=S0186-72102017000100131\&lng=es\&nrm=iso. Acesso em: 12 dez. 2020.

McCARTHY, Bill; WILLIAMS, Monica; HAGAN, John. Homeless youth and the transition to adulthood. In: FURLONG, Andy. Handbook of youth and young adulthood: new perspectives and agendas. Londres: Routledge, 2009. p. 232-239.

MEIRELLES, Melina; DAINESE, Roberto; FRISO, Valeria. A Educação especial no contexto italiano: o projeto de vida, da escola à vida adulta. Revista Educação Especial, Santa Maria, v. 30, n. 57, p. 189-201, jan./abr. 2017.

MELLO, Juliana Leitão E. Jovens em mudança: padronização e despadronização da transição para a vida adulta no Brasil Rio de Janeiro. 2015. Tese (Doutorado em Sociologia) - Universidade do Estado do Rio de Janeiro, Rio de Janeiro, 2015.

MILLER, Dinorah; ARVIZU, Vanessa. Ser madre y estudiante. Una exploración de las características de las universitarias com hijos y breves notas para su estudio. Revista de la Educación Superior, México, v. 45, n. 177, p. 17-42, 2016.

MORA SALAS, Minor; OLIVEIRA, Orlandina de. Los caminos de la vida: acumulación, reproducción o superación de las desventajas sociales en México. Revista Mexicana de Ciencias Políticas y Sociales, México, v. 59, n. 220, p. 81-116, enero/abr. 2014.

MORA SALAS, Minor; OLIVEIRA, Orlandina de. Responsabilidades familiares y autonomía personal: elementos centrales del proceso de transición a la vida adulta. Estudios sociológicos, México, v. 27, n. 81, p. 801-835, 2009.

MORENO, Almudena. The transition to adulthood in spain in a comparative perspective: the incidence of structural factors. Young, [s. l.], v. 20, n. 1, p. 19-48, 2012.

MULDER, Clara H. Leaving the parental home in young adulthood. In: FURLONG, Andy. Handbook of youth and young adulthood: new perspectives and agendas. Londres: Routledge, 2009. p. 203-210.

MÜLLER, Elaine. A transição é a vida inteira: uma etnografia sobre os sentidos e a assunção da adultez. 2008. Tese (Doutorado em Antropologia) - Universidade Federal de Pernambuco, Recife, 2008.

NASCIMENTO, Arlindo Mello do. Transições para a vida adulta: Revisão bibliográfica e olhar na situação brasileira no período 1970-2000. 2006. Dissertação (Mestrado em Estudos Populacionais e Pesquisas Sociais) - Escola Nacional de Ciências Estatísticas, Rio de Janeiro, 2006.

NASCIMENTO, Raquel Coelho; ÁLVARO ESTRAMIANA, José Luis. Alargamiento de la juventude e identidade: un estudio de los procesos de transición a la vida adulta de jóvenes en Brasil y España. Athena Digital, Bellaterra, v. 14, n. 2, p. 21-37, jul. 2014

NOELL, Judit Fullana et al. La transición a la vida adulta de jóvenes con discapacidad intelectual. Evaluación de un programa de formación para la mejora de las competencias personales. Revista de Investigación en Educación, Espanha, v. 13, n. 1, p. 53-68, 2015.

OTERO, Analia Elizabeth. Las configuraciones de transiciones juveniles. Debates actuales sobre la educación y el trabajo. Revista Electrónica de Investigación Educativa, México, v. 13, n. 2, p. 149-165, 2011. Disponível em: http://www. scielo.org.mx/scielo.php?script=sci_abstract\&pid=S1607-40412011000200010\&lng=es\&nrm=i. Acesso em: 11 jun. 2017.

PAIS, José Machado; CAIRNS, David; PAPPÁMIKAIL, Lia. Jovens europeus: retrato da diversidade. Tempo Social, São Paulo, v. 17, n. 2, p. 109-140, 2005. 
PAIS, José Machado. Emprego juvenil e mudança social: velhas teses, novos modos de vida. Análise Social, Lisboa, v. 26, n. 114, p. $945-987,1991$.

PALMA-GARCÍA, Maria de las Olas; RUIZ MOSQUERA, Ana Cristina; VIVES GONZÁLEZ, Célia Luna. Jóvenes inmigrantes extutelados. El tránsito a la vida adulta de los menores extranjeros no acompañados en el caso español. EHQUIDAD, Espanha, n. 12, p. 31-52, jul./dic. 2019. Disponível em: https://revistas.proeditio.com/ehquidad/article/ view/3079. Acesso em: 12 dez. 2020

PEREGRINO, Mônica. Juventude, trabalho e escola: elementos para análise de uma posição social fecunda. Cadernos Cedes, Campinas, v. 31, n. 84, p. 275-291, maio/ago. 2011.

PEREZ, María Leticia Rivermar. En un porvenir incierto. La transición a la adultez entre jóvenes de un municipio de la Sierra Norte de Puebla, México. Norteamérica, México, v. 7, n. 1, p. 99-124, enero/jun. 2012.

PIMENTA, Melissa de Mattos. "Ser jovem” e "Ser adulto": identidades, representações e trajetórias. 2007. Tese (Doutorado em Sociologia) - Faculdade de Filosofia, Letras e Ciências Humanas, Universidade de São Paulo, São Paulo, 2007.

PORVENMIRE-KIRK, Tiana C.; LINDISTROM, Lauren; BULLIS, Michael. De escuela a la vida adulta. Career Development for Exceptional Individuals, [s. l.], p. 1-12, 2009.

PUGA RAYO, Ismael et al. Proyectos de vida y oportunidades en la educación media. Nuevas demandas sociales al sistema escolar chileno. Ultima década, Santiago, v. 25, n. 47, p. 118-153, dic. 2017. Disponível em: https://scielo.conicyt. cl/scielo.php?script=sci_arttext\&pid=S0718-22362017000200118\&lng=es\&nrm=iso. Acesso em: 20 dez. 2020.

RAMOS, Vasco. Transitions to Adulthood and Generational Change in Portugal. Societies, [s. l.], v. 8, n. 2, June 2018. Disponível em: https://doi.org/10.3390/soc8020021. Acesso em: 20 dez. 2020.

RIBEIRO, Carlos Antonio Costa. Desigualdades nas transições para a vida adulta no Brasil (1996 e 2008). Sociologia \& Antropologia, Rio de Janeiro, v. 4, n. 2, p. 433-473, 2014.

RIDDELL, Sheila. Disability, exclusion and transition to adulthood. In: FURLONG, Andy. Handbook of youth and young adulthood: new perspectives and agendas. Londres: Routledge, 2009. p. 81-88.

ROBERTI, Eugenia. Hacia una crítica a la sociología de la transición: reflexiones sobre la paradoja de la desinstitucionalización en el análisis de las trayectorias de jóvenes vulnerables en Argentina. Estudios sociológicos, México, v. 35, n. 105, p. 489-516, dic. 2017. Disponível em: http://www.scielo.org.mx/scielo.php?script=sci_arttext\&pi$\mathrm{d}=\mathrm{S} 2448-64422017000300489 \& \operatorname{lng}=\mathrm{es} \& \mathrm{nrm}=\mathrm{iso}$. Acesso em: $10 \mathrm{dez} .2020$.

SÁNCHEZ-GALÁN, Francisco Javier. Transición a la adultez en España antes y en la salida de la crisis económica. Una comparación utilizando el análisis de entropía. Empiria: Revista de metodología de ciencias sociales, Madrid, n. 43, p. 117-136, mayo 2019. Disponível em: http://revistas.uned.es/index.php/empiria/article/view/24301. Acesso em: 30 dez. 2020.

SÁNCHEZ GALÁN, Francisco Javier. Los eventos de transición hacia la adultez en España. La influência de los factores que los determinan. Sociología y tecnociencia: Revista digital de sociología del sistema tecnocientífico, Espanha, v. 10, n. 1, p. 159-179, 2020. Disponível em: https:/dialnet.unirioja.es/servlet/articulo?codigo=7388171. Acesso em: 16 dez. 2020.

SANTOS ORTEGA, Antonio, MARTÍN MARTÍN, Paz. La juventud española en tiempos de crisis paro, vidas precarias y acción colectiva. Sociología del Trabajo, Madrid, n. 75, p. 93-110, 2012. Disponível em: https://revistas.ucm.es/index. php/STRA/article/view/60592. Acesso em: 30 maio 2016.

SIMPSON, Donald; CIESLIK, Mark. Basic skills and transitions to adulthood. Young, [s.l.], n. 15, p. 395-412, Nov. 2007.

SWARTZ, Teresa Toguchi; O'BRIEN, Kirsten Bengtson. Intergenerational support during the transition to adulthood. In: FURLONG, Andy. Handbook of youth and young adulthood: new perspectives and agendas. Londres: Routledge, 2009. p. 217-225.

VAN DE VELD, Cécile. Devenir adulte: Sociologie comparée de la jeunesse en Europe. Paris: PUF, 2008. (Le lien social).

VARELA, Carmen; LARA, Cecilia. Jóvenes de hoy, adolescentes de ayer en Uruguay: maternidad y desempeños. Sociedad y economia, Cali, n. 29, p. 15-37, 2015.

VIEIRA, Joice Melo. Transição para a vida adulta em São Paulo: cenários e tendências sociodemográficas. 2009. Tese (Doutorado em Demografia) - Instituto de Filosofia e Ciências Humanas, Universidade Estadual de Campinas, Campinas, 2009.

Data de submissão: 31/01/2021

Data de aceite: 11/02/2021 